\title{
Provincial Capital Bias and Economic Growth
}

\author{
Wang Meng, Xu Jiahui \\ International Business School, Shaanxi Normal University \\ Xi'an, China \\ hdhn@163.com
}

\begin{abstract}
A provincial capital has an important influence on the development of regional economy as the focus of one province in China. Studying the panel data of 19 provinces from 2000 to 2016, we find there exists provincial capital bias that the ratio of the provincial capital's population in a province is increasing. We construct a regression model to study the influence of provincial capital bias on economic growth. The result shows that provincial capital bias significantly promotes the growth of provincial economy.
\end{abstract}

Keywords-Provincial Capital Bias; Economic Growth; FGLS; Panel Data

\section{INTRODUCTION}

After China's economy enters the new normal, it is important to explore the spatial dividend and restructure urban system. The urban system of a province is mainly reflected in the status of provincial capital city in the province. Provincial capital is the center of gravity of regional economic development. Its scale is closely related to the result of spatial allocation of resources, and affects the development of regional economy directly. This paper finds that the proportion of the population size of the provincial capital city accounts for a continuous increase in the proportion of the population in the province through the study of the national provincial empirical data, which is called the provincial capital city bias. The impact of the provincial capital city bias on the development of the provincial economy is an important issue to be explored.

After compilation of literature, we found that most literature were based on the concept of the law of primate city [1-3], and the provincial capital bias has not been paid enough attention. On the basis of the existing literature, this paper will explore whether provincial capital bias promotes provincial economic growth.

Because of the existence of the household registration system in China, there is a difference between the census register population and the resident population, especially in large and super large cities with high level of development and the small and medium-sized cities with a backward development. It is generally believed that the actual population which provides labor resources and enjoys the service of urban public facilities is the resident population. Economic growth depends on the output of the resident population. The number of resident population can reflect the situation of human capital and the distribution of social resources in a city, so this paper will use the resident population to calculate provincial capital bias. The calculation formula of provincial capital bias is:

$$
\text { bias }=\mathrm{P} 1 / \mathrm{P}
$$

Among formula (1), P1 represents the number of residents in provincial capital cities, and $\mathrm{P}$ indicates the number of permanent residents in the whole province. Taking into account the availability and reliability of the resident population data, this paper makes use of the panel data of 19 provincial administrative regions in China for 2000-2016 years. The 19 provincial administrative regions include Shandong, Jiangsu, Anhui, Guangdong, Guangxi, Hainan, Henan, Hunan, Hubei, Hebei, Shanxi, Inner Mongolia, Sichuan, Guizhou, Yunnan, Ningxia, Shaanxi, Gansu and Xinjiang.

First of all, we calculated provincial capital bias of these 19 provinces. We can draw the following facts. The provincial capital cities of most provincial administrative regions tend to have an increasing trend. Only the provincial capital cities in some provinces tend to keep the same level. For example, Guangdong Province, this is because Shenzhen as the first special economic zone since China's reform and opening up, has developed rapidly with the world-famous "Shenzhen speed", and has become the sub provincial city of Guangdong. It has quickly surpass Guangzhou in the economic scale. Generally speaking, in the process of economic development, economic agglomeration leads to population aggregation, and the dispersion of economy will lead to the dispersion of population. Therefore, the economic development of Shenzhen has led the accumulation of population to a certain extent, it has dispersed the population which was originally to the provincial capital city of Guangzhou, and the provincial capital bias of Guangdong keeps the basic level or even has a declining trend.

By using kernel density estimation, the horizontal axis is the provincial capital bias and the longitudinal axis is a number. The result shows that the peak in 2000 is near the 0.1 of the horizontal axis, and the peak is higher than 10, while the peak's coordinates of the 2016 move to the right and the peak value is obviously reduced. The right trailing is lengthening, which shows that in the 17 years, provincial capital cities tended to rise and the provincial capital bias of more provinces were beyond their concentration. This trend further confirms the law we found: with the acceleration of urbanization, it is 
obviously that the tendency of provincial capital bias keeps increasing.

\section{MODEL, VARIABLE AND DATA}

Based on the availability of data, this paper selected the panel data of 19 provincial administrative regions in 2000-2016 years to study. The data didn't select four municipalities directly under the central government in Shanghai, Beijing, Tianjin and Chongqing. Because of the

$$
\operatorname{lnpy}_{\mathrm{it}}=\alpha_{0}+\alpha_{1} \operatorname{bias}_{\mathrm{it}}+\alpha_{2} \operatorname{lnpk}_{\mathrm{it}}+\alpha_{3} \text { edu }_{\mathrm{it}}+\alpha_{4} \text { foreign }_{\mathrm{it}}+\alpha_{5} \text { nona }_{\mathrm{it}}+\alpha_{6} \text { urbanize }_{\text {it }}+\alpha_{7} \text { fiscal }_{\text {it }}+\alpha_{8} \mathrm{C}_{\mathrm{it}}+\varepsilon_{\mathrm{it}}
$$

The explained variable in formula (2) is logarithmic processing GDP per capita (lnpy). Py indicates that GDP per capita (yuan/person) in the whole province reflects the economic development level of the whole province, and takes the natural logarithm in the model as the explanatory variable. The data of per capita GDP in each province are derived from The China Statistical Yearbook and the statistical yearbooks of various provinces, all converted into the same price in 2000. In the actual model, the population of the variable has been adjusted to the standard of resident population statistics in the actual model because of the difference of the population statistics in some provinces, which affects the per capita GDP value.

Bias represents the provincial capital bias, as the core explanatory variable in the model, reflecting the proportion of the population of the provincial capital city to the size of the population in the province, which is calculated according to the above formula (1). The data of the resident population in various provinces and cities are derived from the statistical yearbook of various provinces and cities, and there is a lack of data in individual years. This paper uses the method of linear fitting to complement the whole. In addition, this paper will use the law of primate city as a replacement variable to test the robustness of the results. According to the formula of the law of primate city proposed by Jefferson, because the data of the largest non-provincial cities in many provinces are missed, so the index has less sample size. The resident population data used in the calculation is derived from the statistical yearbooks of various cities throughout the years. (2):

The following are the other control variables in formula

(1) lnpk represents the per capita material capital stock (yuan / person) and takes the natural logarithm as the explanatory variable in the model. We calculate the capital stock by perpetual inventory method and convert it into the constant price in $2000^{[4]}$. First of all, the price index $(1952=1)$ was formed by the fixed assets of all provinces in 1952 2016 $(1952=1)$, and the value of the fixed assets in 2000 was divided into the price index of fixed assets to form the index of the fixed asset price formation $(2000=1)$ of each province, and the price index of the fixed capital formation in the name of the provinces was then formed to form the price index of the fixed assets obtained the actual fixed capital formation amount $(2000=1)$. Then we use the existing data to calculate the capital stock of the base period of 2000, and take the same depreciation rate $10.96 \%$ to calculate the capital stock of all missing data of Qinghai and Tibet provinces, the two were also eliminated. In addition, Zhejiang, Jiangxi, Jilin, Changchun, these 7 provinces are missing seriously, so they are also eliminated. The data sources of this paper are The Statistical Yearbook of China, The Statistical Yearbook of Chinese Cities and the statistical yearbooks of provinces and municipalities. One regression model is set up below.

provinces in the 2000 2016 year based on 2000. Fixed capital investment data come from all provinces' calendar yearbooks.

(2) edu indicates the per capita education year in the province, reflecting the abundance of human resources. The data are derived from the Chinese urban statistical yearbook and the lack of data in part of the year. The population in the population over 6 years old and above the provincial Statistical Yearbook is calculated by the formula $\left(\right.$ edu $_{\text {it }}=6 *$ prem $_{\text {it }}+9 *$ junior $_{\text {it }}+12 *$ senior $_{\text {it }}+16 *$ colle $\left._{\text {it }}\right)$ of the population ratio of all kinds of education.

(3) Foreign indicates the import and export volume of the province accounted for GDP, reflecting the degree of opening up to the outside world. For cities with a longer coastline and more ports, their foreign trade is more developed, which has a significant positive impact on economic development.

(4) Nona represents the proportion of non-agricultural economic output in the province accounts for the proportion of GDP. This paper calculates the total output of provincial second or third industry output / the province's GDP. The data are derived from the annual statistical yearbook of China.

(5) Urbanize represents the level of urbanization, that is the proportion of non-agricultural population in the province, reflecting the level of urbanization in the sense of population, or the level of urbanization. The data are derived from the years of China's statistical yearbook and the annual statistical yearbook of the provinces [5].

(6) Fiscal accounts for the proportion of the government's total fiscal expenditure to GDP, reflecting the degree of government intervention, indicating the concentration of financial resources. The data of the provincial fiscal expenditure come from the statistical yearbook of China.

"C" is the other control variable. We select 19 provincial administrative regions, in order to control the individual fixed effect in different provinces, so we set up 18 virtual variables on the basis of Shandong province. We only set a time trend item instead of setting virtual variables for each year in order to avoid loss degree of freedom.

The descriptive statistics of the above variables are shown in Table 1. In the actual model, this paper will logarithm the per capita GDP and physical capital stock per capita to alleviate the heteroscedasticity problem. Heilongjiang, Liaoning and Fujian, the data of residents in 
TABLE I DESCRIPTIVE STATISTICS OF THE INDICATORS

\begin{tabular}{c|c|c|c|c|c|c|c}
\hline Variable & Dimension & Observations & Mean & Standard Deviation & Minimum & Maximum & VIF \\
\hline py & yuan/per & 323 & 18201.98 & 12786.53 & 2759 & 69407.36 & - \\
\hline bias & $\%$ & 323 & 0.13 & 0.188 & 0.0039 & 0.11 & 1.89 \\
\hline pk & yuan/per & 323 & 44137.84 & 36292.57 & 4074.49 & 209939.30 & 3.52 \\
\hline edu & year & 323 & 8.14 & 0.79 & 5.95 & 9.70 & 3.48 \\
\hline foreign & $\%$ & 323 & 21.38 & 29.09 & 3.21 & 158.07 & 1.64 \\
\hline nona & $\%$ & 323 & -13.49 & 6.08 & -35.45 & -3.29 & 1.82 \\
\hline urbanize & $\%$ & 323 & 39.99 & 13.27 & 5.87 & 69.2 & 3.07 \\
\hline fiscal & $\%$ & 323 & 19.70 & 8.38 & 6.91 & 43.75 & 1.84 \\
\hline
\end{tabular}

\section{REGRESSION RESULTS}

Pretest shows that attention should be paid to autocorrelation and heteroscedasticity in model processing, so this paper chooses FGLS estimation method. Especially considering the long time span of panel data, the autocorrelation problem cannot be solved well by FE method. As a contrast, the regression results of OLS and FE are also listed in Table 2.

TABLE II PROVINCIAL CAPITAL BIAS AND ECONOMIC GROWTH

\begin{tabular}{|c|c|c|c|c|}
\hline & model1 & model2 & model3 & model4 \\
\hline & OLS & FE & FGLS & FGLS \\
\hline bias & $\begin{array}{l}0.389^{*} \\
(1.89)\end{array}$ & $\begin{array}{l}0.389 \\
(1.39)\end{array}$ & $\begin{array}{c}0.399^{* *} \\
(2.46)\end{array}$ & $\begin{array}{c}0.323^{* * * *} \\
(9.09)\end{array}$ \\
\hline lnpk & $\begin{array}{c}0.214^{* * *} \\
(12.42)\end{array}$ & $\begin{array}{c}0.214^{* * * *} \\
(4.92)\end{array}$ & $\begin{array}{c}0.274^{* * * *} \\
(10.05)\end{array}$ & $\begin{array}{c}0.255^{* * *} \\
(43.48)\end{array}$ \\
\hline edu & $\begin{array}{c}0.034^{* * * *} \\
(3.41)\end{array}$ & $\begin{array}{c}0.034^{* *} \\
(2.36)\end{array}$ & $\begin{array}{l}0.010 \\
(1.14)\end{array}$ & $\begin{array}{c}0.008^{* * *} \\
(9.17)\end{array}$ \\
\hline foreign & $\begin{array}{l}-0.000 \\
(-0.99)\end{array}$ & $\begin{array}{l}-0.000 \\
(-0.70)\end{array}$ & $\begin{array}{l}0.001 \\
(1.59)\end{array}$ & $\begin{array}{l}0.001^{* * *} \\
(13.17)\end{array}$ \\
\hline nona & $\begin{array}{c}0.011^{* * * *} \\
(5.05)\end{array}$ & $\begin{array}{l}0.011^{* *} \\
(2.42)\end{array}$ & $\begin{array}{l}0.002 \\
(1.23)\end{array}$ & $\begin{array}{c}0.001^{* * * *} \\
(4.11)\end{array}$ \\
\hline urbanize & $\begin{array}{l}0.002 \\
(1.54)\end{array}$ & $\begin{array}{l}0.002 \\
(0.89)\end{array}$ & $\begin{array}{l}0.001 \\
(1.06)\end{array}$ & $\begin{array}{c}0.000^{* * *} \\
(7.78)\end{array}$ \\
\hline fiscal & $\begin{array}{c}-0.004^{* * * *} \\
(-5.07)\end{array}$ & $\begin{array}{l}-0.004^{* *} \\
(-2.72)\end{array}$ & $\begin{array}{l}-0.002 \\
(-1.64)\end{array}$ & $\begin{array}{c}-0.002^{* * * *} \\
(-9.52)\end{array}$ \\
\hline Provincial dummy variable & control & control & control & control \\
\hline $\mathrm{t}$ & $\begin{array}{l}0.069^{* * *} \\
(20.47)\end{array}$ & $\begin{array}{c}0.069^{* * *} \\
(9.24)\end{array}$ & $\begin{array}{c}0.063^{* * *} \\
(12.64)\end{array}$ & $\begin{array}{l}0.068^{* * *} \\
(76.56)\end{array}$ \\
\hline Constant & $\begin{array}{l}7.016^{* * * *} \\
(37.52)\end{array}$ & $\begin{array}{l}6.660^{* * * *} \\
(14.93)\end{array}$ & $\begin{array}{l}6.510^{* * * *} \\
(23.76)\end{array}$ & $\begin{array}{l}6.687^{* * *} \\
(111.64)\end{array}$ \\
\hline Observations & 323 & 323 & 323 & 323 \\
\hline F/Wald & 3624.565 & 2516.564 & 132360.2 & 437793.90 \\
\hline Intra group autocorrelation & & & handle & handle \\
\hline Inter group heteroscedasticity & & & & handle \\
\hline Cross section autocorrelation & & & & handle \\
\hline
\end{tabular}

Note: $\mathrm{t}$ in brackets is t-test value, ${ }^{*},{ }^{* *},{ }^{* * *}$ represent significant respectively at $10 \%, 5 \%$ and $1 \%$.

In Table 2, model 1 reports the results of OLS estimation, which is significant at 10\% level. Model 2 reports the of which the coefficient of provincial capital bias is 0.39 , estimated results of FE. In order to improve the estimation 
accuracy, the $t$ test is based on the error of clustering robust standard. The estimation coefficient of the provincial capital bias is positive but not significant. In order to further deal with the problem of autocorrelation and heteroscedasticity, model 3 and model 4 adopt FGLS estimation method. Model 3 only deals with the problem of intra group autocorrelation. Model 4 also deals with intra group autocorrelation, inter group heteroscedasticity and cross-sectional autocorrelation issues. Our analysis of regression results is based on model 4. Among them, the coefficient estimation value of core interpretation variable, provincial capital bias, is 0.323 , and the level of $1 \%$ is significant, which indicates that the provincial capital bias has positive effect on economic growth of the province. Provincial capital play their positive externalities, increasing labor supply and human resources, knowledge spillover to promote the development of scientific and technological innovation in the province, and improve the efficiency of the use of public goods. The spread effect brought about by positive externalities can promote the linkage development of neighboring cities, thus promoting the development of the whole province's economy effectively

The estimated value of the per capita material capital stock (lnpk) coefficient is 0.255 , and it is significant at the level of $1 \%$. This shows that the per capita material capital stock can effectively drive the provincial economic development level. The stock of capital reflects the scale of production and the level of technology development in the whole province. The average per capita education level (edu) coefficient is estimated to be 0.008 , and also through the $1 \%$ significant level test, there is a small positive impact on economic development. The coefficients of the foreign and the non-agricultural industry proportion (nona) are all 0.001 , although both of them have passed the $1 \%$ significant test, but the impact is weak. The coefficient of urbanization (urbanize) is estimated to be 0 at the level of $1 \%$, indicating that there is no significant impact on provincial economic growth. Government participation (fiscal), which is reflected by the ratio of fiscal expenditure to GDP, is -0.002 , which is significant at the level of $1 \%$, indicating that the government's participation in the economic level has a negative effect on the economic growth of the province. In addition, the coefficient of time trend term $t$ is estimated to be 0.068 and through a significant level test of $1 \%$, which shows that the economic growth of the province shows a significant trend of growth over time.

\section{CONCLUSION}

On the basis of the theoretical analysis, we uses the panel data of 19 provinces in China during 2000-2016 years to explore the economic impact of provincial capital bias on economic growth. The research found that provincial capital bias promotes the provincial economic growth significantly.

As the political, economic and cultural center of a province, a provincial capital attracts a large number of population. Provincial capital bias should be taken into consideration when provinces adjust the household registration system and the related industrial planning. In order to realize the positive externality of provincial capital bias, it is necessary to relax the policy obstacles to population agglomeration, promote the reform of land and household registration system, promote the flow and reconfiguration of factors, and encourage the transfer of agricultural labor from villages to cities [6].

\section{REFERENCES}

[1] Zhang Haoran, Yi Baozhong, 2012, Spatial Structure and Economic Performance in Chinese Urban Agglomerations, Economic Review, No.1. (In Chinese)

[2] Xu Changsheng, Zhou Zhipeng, 2014, Law of the Primate City and Economic Growth, Finance \& Economics, No.9. (In Chinese)

[3] Soo Kwok Tong, 2004, Zipf's Law for cities: a cross-country investigation, Regional Science and Urban Economics, No.35.

[4] Ke Shanzi, 2009, Analysis on the Growth Poles and Spillovers in the Western and Eastern China, Statistical Research, No.1.(In Chinese)

[5] Wang Meng, Xuan Ye, Chen Qifei, 2016, Creative Class Agglomeration, Knowledge Externalities and Urban Innovation, Economic Theory and Business Management, No.1. (In Chinese)

[6] Lu Ming, Gao Hong, Zuo Tenghong, 2012, Urban Scale and Inclusive Employment, Social Sciences in China, No.10. (In Chinese) 